\title{
Effect of surgical lung volume reduction on respiratory muscle function in pulmonary emphysema
}

\author{
H. Teschler, G. Stamatis, A.A. El-Raouf Farhat, F.J. Meyer, U. Costabel, N. Konietzko
}

Effect of surgical lung volume reduction on respiratory muscle function in pulmonary emphysema. H. Teschler, G. Stamatis, A.A. El-Raouf Farhat, F.J. Meyer, U. Costabel, N. Konietzko. @ ERS Journals Ltd 1996.

ABSTRACT: Lung volume reduction surgery (LVRS) in patients with severe lung emphysema restores the thoracic configuration to a more normal functional capacity. The aim of this study was to investigate whether reduction in intrathoracic volume by LVRS improves the inspiratory muscle force generation of the respiratory pump.

Pulmonary function tests, maximal inspiratory mouth pressure (MIP), sniff nasal inspiratory pressure $(\mathrm{SNIP})$, sniff transdiaphragmatic pressure $\left(\boldsymbol{P}_{\mathrm{di}}\right)$, and inspiratory mouth occlusion pressure $(P 0.1)$ were measured in 17 emphysematous patients (mean $( \pm$ SEM) age $53 \pm 2$ yrs) before and 1 month after LVRS.

The mean value of forced expiratory volume in one second (FEV1) increased $(0.82 \pm 0.07$ vs $1.12 \pm 0.08 \mathrm{~L} ; \mathrm{p}<0.0001)$, whilst there was a decrease $(\mathrm{p}<0.0001)$ in residual volume (RV) $(337 \pm 31$ vs $250 \pm 21 \%$ of predicted), functional residual capacity (FRC) $(210 \pm 9$ vs $159 \pm 9 \%$ pred), and total lung capacity (TLC) $(138 \pm 6$ vs $110 \pm 5 \%$ pred). The mean value of MIP increased by $52 \%$ from $4.8 \pm 0.4$ to $7.3 \pm 0.6 \mathrm{kPa}$ $(p<0.001)$, the mean value of SNIP increased by $66 \%$ from $3.9 \pm 0.4$ to $6.5 \pm 0.5 \mathrm{kPa}$ $(p<0.001)$, and the mean value of $P$ di increased by $28 \%$ from $6.0 \pm 0.6$ to $7.7 \pm 0.8 \mathrm{kPa}$ $(\mathrm{p}<0.05)$ after LVRS. $P 0.1$ decreased on average by $24 \%$ from $0.46 \pm 0.03$ to $0.35 \pm 0.02$ kPa after LVRS. No significant correlations were found between inspiratory muscle $\left(\mathrm{MIP}, \mathrm{SNIP}, P_{\mathrm{di}}\right)$ and respiratory drive $(P 0.1)$ indices, lung function data, $6 \mathrm{~min}$ walk distance, or dyspnoea score.

In conclusion, the observed clinical improvement of patients with severe emphysema after lung volume reduction surgery results, in part, from an increased ability of the inspiratory muscles to generate force, which is paralleled by a significant decrease in central respiratory drive.

Eur Respir J., 1996, 9, 1779-1784.
Ruhrlandklinik, Essen, Germany.

Correspondence: H. Teschler

Ruhrlandklinik

Tüschener Weg 40

D-45239 Essen

Germany

Keywords: Emphysema

lung volume reduction

pulmonary function

respiratory muscle function

Received: February 271996

Accepted after revision June 111996
Severe emphysema of the lung results in detrimental abnormalities in ventilatory mechanics, such as increased airway resistance, diaphragmatic inefficiency, and dynamic hyperinflation [1-4]. Hyperinflation of the lung impairs the efficiency of the muscles of the chest wall and diaphragm by placing them at mechanical disadvantage [4]. The relationship between mechanical abnormalities of rib cage and diaphragm and respiratory muscle function has been studied in animals [5], and in patients with pulmonary emphysema [6-9]. The adverse effects of hyperinflation on diaphragmatic function include foreshortening of diaphragm precontraction length $[1,3,6$, $10,11]$, decreased area of apposition of the costal part with the chest wall $[7,8]$, increased radius of curvature [1], impaired blood flow and decreased insertional action on the rib cage [12], and increased internal elastic inspiratory load $[3,4]$.

The most widely-applied method of determining global inspiratory strength is the measurement of mouth pressure during maximal inspiratory efforts (MIP), which has been shown to be decreased in severe emphysema [9]. Some investigators have determined the sniff nasal inspiratory pressure (SNIP) as a measure of inspiratory muscle strength; a manoeuvre which is easier to perform for most subjects [13-16]. SNIP values were lower in patients with emphysema than in normals, but underestimated strength compared to MIP [16, 17]. Others have measured the transdiaphragmatic pressure $(P \mathrm{di})$ either during voluntary static or sniff contraction or phrenic nerve stimulation [18-20], to estimate diaphragmatic strength in patients with emphysema more specifically. The reported studies clearly indicate that the transdiaphragmatic pressure is reduced in emphysema. However, the functioning of the diaphragm at equal lung volumes as in normals was found to be similar, suggesting that muscle strength is preserved in emphysema [2].

Respiratory centre drive has also been noted to be increased in chronic obstructive pulmonary disease (COPD) patients with severe hyperinflation of the lung [21-24]. One of the measures of respiratory centre drive, the mouth occlusion pressure $(P 0.1)$, is consistently elevated in severe COPD. This increase in respiratory drive may, at least in part, be explained by the increased resistance to airflow and decreased dynamic pulmonary compliance in patients with COPD [22, 23].

Recently, COOPER and co-workers [25] demonstrated that the newly resurrected technique of lung volume reduction surgery (LVRS) can be of significant clinical value 
for selected patients with severe emphysema. A series of 100 patients [26] showed significant improvement of lung function, gas exchange, $6 \mathrm{~min}$ walking distance, dyspnoea, and quality of life 3 months after bilateral surgical lung reduction. Since the mechanical efficiency of the rib cage and diaphragm is sensitive to changes in lung volume $[1,3,9,10,19]$, LVRS may improve the performance of the respiratory muscles and, thus, reduce dyspnoea.

Our hypothesis was that LVRS beneficially affects the respiratory pump. This hypothesis was tested by measuring indices of global inspiratory muscle force generation, diaphragmatic muscle strength, and respiratory drive in patients with severe emphysema before and 1 month after LVRS.

\section{Methods}

\section{Patients}

Seventeen patients ( 2 females and 15 males; mean \pm SEM age $53 \pm 2$ yrs; age range $38-63$ yrs) with severe emphysema and dyspnoea on minimal exertion participated in this study. The diagnosis was based on physical examination, chest radiograph, computed tomography (CT) scan, lung perfusion scan, and pulmonary function data. None of the patients had a history of asthma and their airflow obstruction was irreversible. Patients with an arterial carbon dioxide tension $\left(P \mathrm{a}, \mathrm{CO}_{2}\right)>6 \mathrm{kPa}(45 \mathrm{mmHg})$ or evidence of left ventricular failure were excluded. One patient had a history of treated pulmonary tuberculosis.

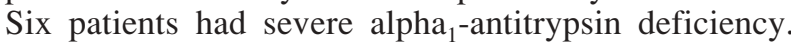
Three of the alpha ${ }_{1}$-antitrypsin deficient patients were lifelong nonsmokers, and the other 11 patients had stopped smoking at least 3 months before surgery. Six patients had not been chronically treated with corticosteroids and 12 patients were taking less than $20 \mathrm{mg}$ prednisolone orally per day. Three patients underwent a bilateral LVRS via median sternotomy $(\mathrm{n}=2)$ or bilateral thoracotomy, nine a LVRS of their right lung and five of their left lung via thoracotomies. All patients gave their written informed consent.

Physiological assessment included: dyspnoea score, 6 min walk test, pulmonary function tests, and arterial blood gas analysis. All measurements were performed during the week before surgery and approximately 1 month after surgery. At the same time intervals, measurements of respiratory muscle strength and respiratory drive were performed as described below.

\section{Quantification of dyspnoea}

A modified Medical Research Council (MRC) Dyspnoea Scale was used to quantify the degree of dyspnoea [25, 27].

\section{Six minute walk test}

A 6 min walk test was performed according to standard procedures $[25,28]$. All tests were conducted in a straight $18 \mathrm{~m}$ corridor, with the same trained supervisor giving encouragement to the subject to cover as much ground as possible in $6 \mathrm{~min}$. The distance walked was measured.

\section{Lung function testing}

Lung volumes were measured by body plethysmography (Bodybox; Fenyves and Gut, Bodelshausen, Germany) and included inspiratory vital capacity (IVC), forced expiratory volume in one second (FEV1), FEV1/FVC, functional residual capacity (FRC), residual volume (RV), total lung capacity (TLC), and airway resistance (Raw). The data were expressed as percentage of predicted in each patient. Arterial blood was sampled from the radial artery while patients were breathing room air at rest, and blood gas values were measured using an automatic blood gas analyser (AVL, Bad Homburg, Germany).

\section{Maximum inspiratory pressure}

MIP was measured during forceful efforts against a closed mouth valve starting at RV, as described by BLACK and Hyatт [29]. The tests were performed in the sitting position with a noseclip in place. The reported values represent the best effort of six trials.

\section{Sniff nasal pressure}

The SNIP was measured with a pressure transducer connected to a plug in one nostril during a sniff performed through the contralateral nostril, as described by HERITIER et al. [13], using a commercially available system kindly provided by Zan (Zan 400 Sniff; Waldfenster, Germany). Criteria for a suitable sniff were a regular upstroke and sharp peak and a total sniff duration of less than $0.5 \mathrm{~s}$. The tests were performed in the sitting position. The reported values represent the best effort of six trials.

\section{Transdiaphragmatic pressure}

The $P$ di was measured with two commercially available $10 \mathrm{~cm}$ balloon catheters (PK Morgan, Rainham, UK) each coupled to a pressure transducer. The tip of the gastric balloon to measure gastric pressure $(\mathrm{Pga})$, containing $2-3 \mathrm{~mL}$ of air, was positioned $55-60 \mathrm{~cm}$ from the nares. The oesophageal balloon to measure oesophageal pressure $\left(P_{\mathrm{oes}}\right)$ was positioned in the middle third of the oesophagus and contained $0.5 \mathrm{~mL}$ of air. $P$ di was derived electronically (Zan 400 Pdi; Waldfenster, Germany) according to the equation: $P_{\mathrm{di}}=P_{\mathrm{ga}}-P_{\mathrm{oes}}$, and $P_{\mathrm{di}}$ at resting end-expiration was used as the zero reference point. All subjects were studied in the sitting position and were asked to perform at least six short sharp sniffs as hard as possible with more than two quiet breaths between each sniff [15]. Pdi recordings were displayed in front of the patient for visual feedback to encourage maximal efforts. The highest value recorded was used for further analysis.

\section{Mouth occlusion pressure}

Mouth occlusion pressure $0.1 \mathrm{~s}$ after the beginning of inspiration $\left(P_{0.1}\right)$ was measured in the sitting position 
Table 1. - Pulmonary function data of the 17 study patients with severe emphysema 1 week before and 1 month after lung volume reduction (LVRS) surgery

\begin{tabular}{lccc}
\hline & Before LVRS & After LVRS & p-value \\
\hline Dyspnoea score $\mathrm{n}$ & $3.4 \pm 0.2$ & $1.6 \pm 0.2$ & $<0.0001$ \\
6 min walk m & $229 \pm 18$ & $405 \pm 23$ & $<0.0001$ \\
IVC \% pred & $54 \pm 3$ & $57 \pm 3$ & $\mathrm{NS}$ \\
$\mathrm{RV} \%$ pred & $337 \pm 31$ & $250 \pm 21$ & $<0.0001$ \\
$\mathrm{FRC} \%$ pred & $210 \pm 9$ & $159 \pm 9$ & $<0.0001$ \\
TLC \% pred & $138 \pm 6$ & $110 \pm 5$ & $<0.0001$ \\
$\mathrm{FEV} 1 \%$ pred & $31 \pm 2$ & $41 \pm 2$ & $<0.0001$ \\
$\mathrm{FEV} 1 \mathrm{~L}$ & $0.8 \pm 0.07$ & $1.1 \pm 0.08$ & $<0.0001$ \\
$\mathrm{FEV} 1 / \mathrm{IVC}$ & $43 \pm 3$ & $57 \pm 3$ & $<0.0001$ \\
$R \mathrm{aw} \mathrm{kPa} \cdot \mathrm{L}-1 \cdot \mathrm{s}$ & $0.57 \pm 0.07$ & $0.44 \pm 0.05$ & $<0.001$ \\
$\mathrm{~Pa}_{\mathrm{a}} \mathrm{O}_{2} \mathrm{mmHg}$ & $64 \pm 2$ & $70 \pm 3$ & $<0.001$ \\
$\mathrm{~Pa}_{\mathrm{a}} \mathrm{CO}_{2} \mathrm{mmHg}$ & $40 \pm 2$ & $37 \pm 1$ & $\mathrm{NS}$ \\
\hline
\end{tabular}

IVC: inspiratory vital capacity; RV: residual volume; FRC: functional residual capacity; TLC: total lung capacity; FEV1: forced expiratory volume in one second; Raw: airway resistance; $\%$ pred: percentage of predicted value; $P_{\mathrm{a}, \mathrm{O}_{2}}$ : arterial oxygen tension; $P \mathrm{a}, \mathrm{CO}_{2}$ : arterial carbon dioxide tension; NS: nonsignificant. $1 \mathrm{mmHg}=0.133 \mathrm{kPa}$.

with a commercially available recorder (Andos, Hamburg, Germany) as described previously [22, 23]. Occlusion pressure was determined from the mean of six measurements.

\section{Statistical analysis}

All data are given as mean \pm SEM. Statistical significance was determined by the paired t-test. Correlation was calculated using the Spearman correlation coefficient. A pvalue of less than 0.05 was considered significant.

\section{Results}

The results of the dyspnoea score, 6 min walk test, lung function data, and blood gas analysis before and after LVRS are summarized in table 1.

The results for MIP, SNIP, and $P$ di are shown in figure 1. The MIP measurements were reproducible, with a mean coefficient of variation for values within the same subject of less than $12 \%$. The amplitude of MIP increased in 16 of the 17 patients and on average by $52 \%$ from $4.8 \pm 0.4$ before to $7.3 \pm 0.6 \mathrm{kPa}$ after LVRS $(\mathrm{p}<0.0001)$ (fig. 1a). There was a positive correlation $(r=0.86)$ between MIP before and after surgery. The difference of MIP before and after surgery did not correlate with the improvement of dyspnoea score, 6 min walking distance, lung function and blood gas data.

The coefficient of variation for SNIP values within the same subject was less than $17 \%$. SNIP values measured before and after lung volume reduction increased in all study patients, on average by $66 \%$ from $3.9 \pm 0.4$ before to $6.5 \pm 0.5 \mathrm{kPa}$ after LVRS $(\mathrm{p}<0.0001)$ (fig. $1 \mathrm{~b})$. There was a positive correlation $(\mathrm{r}=0.78)$ between SNIP values before and after surgery, but no correlation was found between the difference of SNIP values and the improvement of dyspnoea score, 6 min walking distance, lung function or blood gas data.

The coefficient of variation for $P$ di values within the same subject was less satisfactory $(28 \%)$. Pdi values before and after LVRS were available in only 12 of the 17 patients. There was a clinically important improvement of $P$ di in 10 of 12 patients. The average pressure increased by $28 \%$ from $6.0 \pm 0.6$ before to $7.7 \pm 0.8 \mathrm{kPa}$ after LVRS $(\mathrm{p}<0.01)$ (fig. 1c). There was a positive correlation $(\mathrm{r}=0.81)$ between $P \mathrm{di}$ values before and after surgery. The difference in $P$ di before and after surgery did not correlate with improvement in 6 min walking distance and dyspnoea score, nor with lung function or blood gas data.

Figure 2 shows the effect of LVRS on P0.1. There was a clinically important decrease of $P 0.1$ in 15 of the 17 patients after LVRS. $P 0.1$ decreased on average by $24 \%$ from $0.46 \pm 0.03$ before to $0.35 \pm 0.02 \mathrm{kPa}$ after surgery $(\mathrm{p}<0.0001)$. Although significantly reduced after surgery, $P 0.1$ remained above the upper limit of normal $(0.25 \mathrm{kPa})$ in 13 of the 17 subjects. There was a significant correlation $(\mathrm{r}=0.69)$ between the $P 0.1$ values before and after LVRS. No correlation was found between the change of $P_{0.1}$ and the improvement in 6 min walking distance and dyspnoea score, nor between lung function or blood gas data.

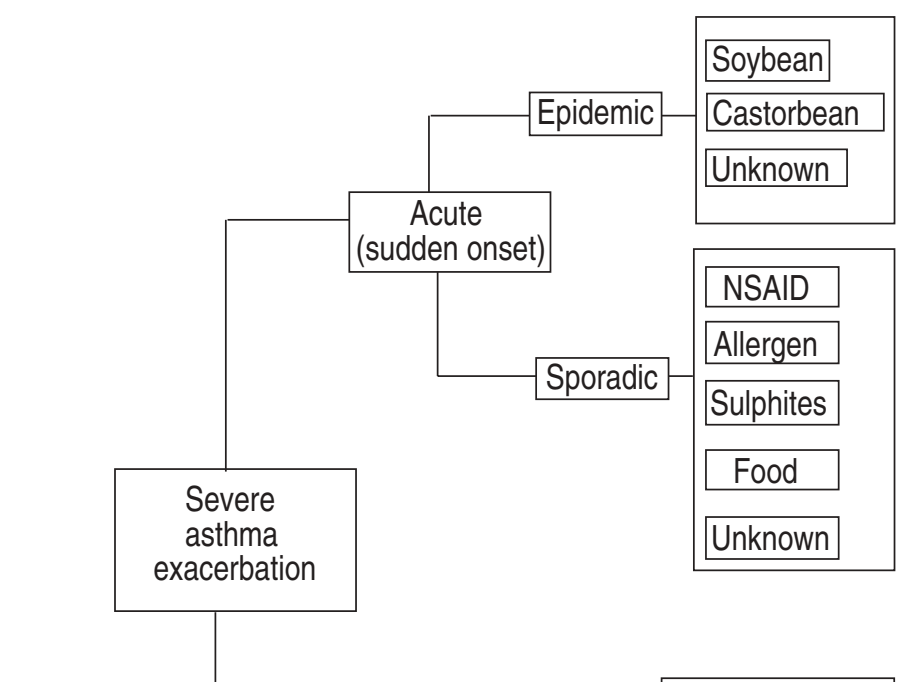

Fig. 1. - Various parameters of respiratory muscle performance 1 week before and 1 month after lung volume reduction surgery (LVRS). a) Changes in maximal inspiratory mouth pressure (MIP); b) changes in sniff nasal inspiratory pressure (SNIP); c) changes in transdiaphragmatic pressure $(P \mathrm{di})$. Mean values \pm SEM are shown. 


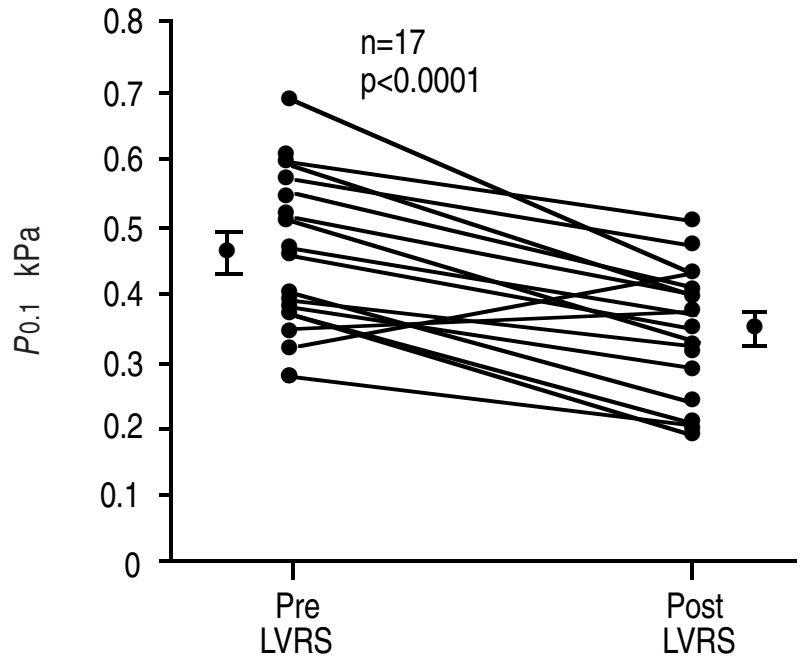

Fig. 2. - Mouth occlusion pressure $\left(P_{0.1}\right) 1$ week before and 1 month after lung volume reduction surgery (LVRS). Mean values \pm SEM are shown.

\section{Discussion}

This study demonstrates that in patients with severe emphysema the impaired respiratory muscle performance can be improved by LVRS. Moreover, the improved respiratory muscle performance is associated with a significant reduction in the ventilatory drive as measured by the $P 0.1$.

The loss of pulmonary parenchyma in emphysema decreases the elastic recoil of the lung $[2,3,10,19,30$, 31]. This results in an abnormally low expiratory flow rate, increased expiratory airway resistance, and a greater lung volume at any given transpulmonary pressure [19, 30, 31]. This leads to increased TLC, FRC and RV. Dynamic air-trapping further increases FRC. The hyperinflation impairs the function of the inspiratory muscles due to shorter operative fibre length and flattening of the diaphragm [9, 19, 20, 29, 30].

LVRS has been shown to increase elastic recoil, perhaps by selectively removing highly compliant regions or by tethering regional and more remote lung parenchyma $[25,31]$. The observed improvement in MIP after LVRS is reliable, because measurements were satisfactorily reproducible and patients were carefully coached to perform their best efforts. The most likely explanation for the observed improvement in MIP is an increase in elastic recoil, leading in turn to improved resting muscle length and diaphragm geometry. This is consistent with published data from Sciurba et al. [31], demonstrating an increase of maximal transpulmonary pressure as indicator of elastic recoil from 9.5 to $12.1 \mathrm{cmH}_{2} \mathrm{O}$ after LVRS

MIP is the most widely-used noninvasive test of global inspiratory muscle performance in clinical practice $[9$, 29]. However, MeAD et al. [32] have reported that the antagonistic contraction of the abdominal muscles may limit the development of high inspiratory mouth pressures in untrained subjects, and many older patients have particular difficulties with this static technique. LAROCHE et al. [14] showed that inspiratory muscle strength is better reflected by the oesophageal pressure changes during a maximal sniff than by the static mouth pressure after a forceful inspiratory effort. According to HERITIER et al. [13], the same information can be obtained by measuring SNIP in one occluded nostril whilst sniffing through the contralateral nostril. SNIP has the advantage of being a noninvasive measure involving a more natural manoeuvre for most subjects. Alterations of lung mechanics are known to reduce the transmission of alveolar pressure to the upper airways [16], as would functional obstruction of the upper airways. However, in the present study population, consisting of patients with severe emphysema, the SNIP was satisfactorily reproducible with a coefficient of variation within the same subject of less than $17 \%$. LVRS resulted in a mean increase of SNIP from 3.9 to $6.5 \mathrm{kPa}$, which was on average higher than the observed increase of MIP. ULDRY and FITTING [17] observed that SNIP underestimates strength compared to MIP, because it is a shorter manoeuvre. In COPD, transmission of the pressure response from oesophagus to mouth and nose takes longer than in individuals with normal airway resistance and conductance. Therefore, the more pronounced increase in SNIP after LVRS may be partially explained by improved pressure transmission, and not only by improved respiratory muscle strength. Nevertheless, the present study demonstrates that SNIP is a potentially useful noninvasive measurement to monitor respiratory muscle strength after LVRS, especially in patients with difficulties in reproducing static manoeuvres.

$P$ di has been shown to decrease with increasing lung volume in control subjects as well as patients with COPD $[18,20]$. In the present study population of patients with severe emphysema, the amplitude of the $P$ di varied widely among subjects, but was significantly reduced compared with our laboratory and published reference values $[15,18,20]$. The sniff technique [15] had the advantage of ease of performance for the patients. In spite of the broad range of $P$ di values after LVRS, the increase in $P$ di after LVRS was significant. However, $P$ di values remained in most patients at levels much lower than those in normal subjects. The persistent abnormality in $P$ di is consistent with the incomplete restoration of the curvature of the flattened diaphragm after LVRS. It is important to emphasize that the noninvasive tests, MIP $(+52 \%)$ and SNIP $(+66 \%)$, demonstrated a better improvement of respiratory muscle performance than did $P$ di $(+28 \%)$, probably because MIP and SNIP reflect the combined strength of all respiratory muscles (rib cage, diaphragm, and abdominal wall). From a clinical perspective, the present data indicate that most changes in respiratory muscle function after LVRS can be estimated by the simple measurement of MIP and SNIP. Since the determination of $P$ di does not substantially contribute to the clinical management, the technical difficulties preclude the routine use of this invasive measurement to monitor patients after LVRS.

The $P 0.1$ has been found to be useful in assessing respiratory centre and neuromuscular coupling in patients with COPD [22-24]. If $P 0.1$ is considered an index of central inspiratory drive, the results from the present study are in agreement with earlier studies, demonstrating that patients with severe emphysema have a high respiratory centre output, despite certain mechanical disadvantages of the inspiratory muscles resulting from the hyperinflated lung [23, 24]. In 15 of the 17 patients a significant decrease of $P 0.1$ was observed after LVRS. These 
improvements may be partially explained by the observed decrease in airway resistance and residual volume after LVRS, since occlusion pressure response to flow resistive loading is increased in COPD patients [16, 21]. In particular, flow resistive loading is increased in severe emphysema as a result of reduced elastic recoil and increased airway resistance.

There are two other possible explanations for the decrease of $P 0.1$ after LVRS. Firstly, $P 0.1$ might return towards normal because of a significant reduction in the work of breathing and of intrinsic positive end-expiratory pressure (PEEP), as hypothesized by COOPER and co-workers [26]. Secondly, improvement of oxygenation is associated with a decrease in respiratory centre drive as measured by $P 0.1$. This hypothesis has been suggested by the finding that COPD patients reduce their $P 0.1$ during oxygen breathing [23]. Nevertheless, the $P 0.1$ values 1 month after LVRS remained, in 13 of the 17 patients, at levels higher than those in normal subjects despite an average increase in arterial oxygen tension $\left(\mathrm{Pa}, \mathrm{O}_{2}\right)$ from 8.5 to $9.3 \mathrm{kPa}$ (64 to $70 \mathrm{mmHg}$ ) after LVRS. The residual increase in respiratory drive could be due to adaptive processes to chronic hypoxia which are not completely reversed after 1 month or due to the fact that the mechanical load of breathing, albeit reduced after surgery, was still elevated at 1 month. Follow-up studies are required to determine whether mechanical or chemical effects predominate in the persistently increased respiratory drive of patients with severe emphysema after LVRS.

In conclusion, this study demonstrates that the clinical improvement seen in patients with severe emphysema following lung volume reduction surgery is due not only to an improved pulmonary function related to the increased elastic recoil but also to an increased ability of the respiratory muscle to generate force and a decreased respiratory drive presumably because of a reduced work of breathing.

Members of the Ruhrlandklinik Lung Volume Reduction Study Group: Dept of Pneumology: A.A. Farhat, N. Konietzko, M. Leiendecker, F.J. Meyer, S. Redecker, H. Steveling, H. Teschler; Dept of Pneumology/Allergy: P.C. Bauer, U. Costabel, H. Wohland; Dept of Thoracic Surgery: S. Fechner, D. Greschuchna, G. Stamatis, E. Tekolf; Dept of Anesthesia and Intensive Care: J. Bortel, M. Rocha-Patino, V. Weißkopf.

\section{References}

1. Minh V, Dolan GF, Konopka RF, Moser KM. Effect of hyperinflation on inspiratory function of the diaphragm. J Appl Physiol 1976; 40: 67-73.

2. Similowski T, Sheng Y, Gauthier AP, Macklem PT, Bellemare F. Contractile properties of the human diaphragm during chronic hyperinflation. $N$ Engl J Med 1991; 325: 917-923.

3. Smith J, Bellemare F. Effect of lung volume on in vitro contraction characteristics of human diaphragm. J Appl Physiol 1987; 62: 1893-1900.

4. Younes M. Load responses, dyspnoea and respiratory failure. Chest 1990; 97: 59s-68s.

5. Supinski GS, Kelsen SG. Effect of elastase-induced emphysema on the force-generating ability of the diaphragm. J Clin Invest 1982; 70: 978-988.
6. Evanich MJ, Franco MJ, Lourenco RV. Force output of the diaphragm as a function of phrenic nerve firing rate and lung volume. J Appl Physiol 1973; 35: 208-212.

7. Loring SH, Mead J. Action of the diaphragm on the rib cage inferred from a force-balance analysis. J Appl Physiol: Respirat Environ Exercise Physiol 1982; 53: 756-760.

8. Mead J. Functional significance of the area of apposition of diaphragm to rib cage. Am Rev Respir Dis 1979; 119 (Suppl.): 31-32.

9. Rochester DG, Braun NMT, Arora NS. Respiratory muscle strength in chronic obstructive disease. Am Rev Respir Dis 1979; 119: 151-154.

10. Sharp JT, Danon J, Druz WS. Respiratory muscle function in patients with chronic obstructive pulmonary disease: its relationship to disability and to respiratory therapy. Am Rev Respir Dis 1974; 110: 154-167.

11. Rochester DF, Braun NMT. Determinants of maximal inspiratory pressure in chronic obstructive pulmonary disease. Am Rev Respir Dis 1985; 132: 42-47.

12. D'Angelo E, Santa'Ambrogio G. Direct action of contracting diaphragm on the rib cage in rabbits and dogs. J Appl Physiol 1974; 36: 715-719.

13. Heritier F, Rahm F, Rasche P, Fitting JW. Sniff nasal inspiratory pressure. Am J Respir Crit Care Med 1994; 150: $1687-1683$.

14. Laroche CM, Mier AK, Moxham J, Green M. The value of sniff oesophageal pressure in the assessment of global inspiratory muscle strength. Am Rev Respir Dis 1988; 138: 598-603.

15. Miller JM, Moxham J, Green G. The maximal sniff in the assessment of diaphragm function in man. Clin Sci 1985; 69: 91-96.

16. Murciano D, Aubier M, Bussi S, Derenne JP, Pariente R, Milic-Emili J. Comparison of oesophageal, tracheal, and mouth occlusion pressure in patients with chronic obstructive pulmonary disease during acute respiratory failure. Am Rev Respir Dis 1982; 126: 837-841.

17. Uldry C, Fitting J. Influence of airway obstruction on sniff nasal inspiratory pressure. Am J Respir Crit Care Med 1995; 151: A414.

18. Gibson GJ, Clark E, Pride NB. Static transdiaphragmatic pressure in normal subjects and in patients with chronic hyperinflation. Am Rev Respir Dis 1981; 124: 685-689.

19. Hamnegrad CH, Wragg S, Mills G, et al. The effect of lung volume on transdiaphragmatic pressure. Eur Respir $J$ 1995; 8: 1532-1536.

20. Lapota D, Graddino A. Assessment of transdiaphragmatic pressure in humans. J Appl Physiol 1985; 58: 1469-1476.

21. Lapato M, Önal E, Cromydas G. Respiratory load compensation in chronic airway obstruction. J Appl Physiol 1985; 59: 1947-1954.

22. Gorini M, Spinelli A, Ginanni R, Duranti R, Gigliotti F, Scano G. Neural respiratory drive and neuromuscular coupling in patients with chronic obstructive pulmonary disease (COPD). Chest 1990; 98: 1179-1186.

23. Grassion A, Sörli J, Lorange G, Milic-Emili J. Respiratory drive and timing in chronic obstructive pulmonary disease. Chest 1978; 73: 290-292.

24. Kelsen SG, Fleegler B, Altos MD, Gottfried S, Cherniack NS. Effects of hypercapnia and flow resistive loading on respiratory activity in asthma and chronic obstructive lung disease. Chest 1978; 73: 288-290.

25. Cooper JD, Trulock EP, Triantafillou AN, et al. Bilateral pneumectomy (volume reduction) for chronic obstructive pulmonary disease. J Thorac Cardiovasc Surg 1995; 109: 106-119. 
26. Cooper JD, Patterson GA. Lung volume reduction surgery for severe emphysema. Surg Clin North Am 1995; 5: 815-830.

27. Mahler DA, Weinberg DH, Wells CK, Feinstein AR. The measurement of dyspnea: contents, interobserver agreement, and physiologic correlates of two new clinical indexes. Chest 1984; 85: 751-758.

28. Guyatt GH, Pugsley SO, Sullivan MJ, et al. Effect of encouragement on walking test performance. Thorax 1984; 39: 818-822.

29. Black LF, Hyatt RE. Maximal respiratory pressure: normal values and relationship to age and sex. Am Rev Respir Dis 1969; 99: 696-702.

30. Sharp JT. The respiratory muscle in emphysema. Clin Chest Med 1983; 4: 421-432.

31. Sciurba FC, Rogers RM, Keenan RJ, et al. Improvement in pulmonary function and elastic recoil after lung reduction surgery for diffuse emphysema. N Engl J Med 1996; 334: 1095-1096.

32 . Mead J, Milic-Emili J, Turner JM. Factors limiting depth of a maximal inspiration in human subjects. $J$ Appl Physiol 1963; 18: 295-296. 